\title{
Postoperative Outcome Comparison between Manual Dilatation and Lateral Internal Anal Sphincterotomy in the Treatment of Chronic Anal Fissure
}

\author{
MOHAMED IBRAHIM SHALAMESH, M.D. \\ The Department of General Surgery, Faculty of Medicine (Boys), Al-Azhar University
}

\begin{abstract}
Background: In latest days, medicinal cure for chronic anal fissure has replaced surgical surgery. Internal anal sphincter hypertonia is an uncomfortable disorder that affects many people. This study compared the results of surgical treatment of chronic anal fissure after lateral internal sphincterotomy with manual dilatation of anus.
\end{abstract}

Aim of Study: This study was aimed to contrast the outcomes of total lateral internal anal sphincterotomy and manual dilatation of anus in terms of symptoms and postoperative complications.

Patients and Methods: This randomized controlled prospective Cohort study was conducted on 100 patients of chronic anal fissure with pain and bleeding. They were allocated to manual dilatation $(n=50)$ or to lateral internal anal sphincterotomy $(\mathrm{n}=50)$.

Results: The mean \pm SD postoperative pain VAS score of MAD group is higher than LAS group after 12 hours (6.72 \pm 0.757 vs $5.46 \pm 0.579)$, 24 hours ( $3.42 \pm 0.642$ vs $2.86 \pm 0.452$ ) and 48 hours $(0.50 \pm 0.544$ vs $0.46 \pm 0.542)$. There is a notable change in postoperative pain VAS score in between MAD and LAS groups at 12 and 24 hours $(p<0.0001)$. Furthermore, there is no significant change in postoperative pain VAS score between the MAD and LAS groups after 48 hours ( $p=0.698$ ),

Conclusion: Lateral anal sphincterotomy is better than anal dilatation in the management of chronic anal fissure in terms of early symptomatic relief, shorter hospital stay and less complication rate.

Key Words: Anal sphincter - Chronic anal fissure - Lateral internal anal sphincterotomy - Manual dilatation of anus.

\section{Introduction}

A LINEAR ulcer of the anoderm distal to the dentate line is known as an anal fissure. It is usually found in the midline of the posterior anoderm. Anal fissure of less than 6 weeks duration is called

Correspondence to: Dr. Mohamed Ibrahim Shalamesh, The Department of General Surgery, Faculty of Medicine (Boys), Al-Azhar University acute but if persist for more than 6 weeks called chronic [1].

Chronic anal fissure may also possess associated sentinel piles, hypertrophied anal papillae or visible internal sphincter fibers. Though its prevalence is not known in our context, chronic anal fissure is very commonly seen in day-to-day clinical practice [2].

Chronic fissures are usually deeper and have exposed internal sphincter fibers at their base. It has a hypertrophy anal papilla at the proximal end and a sentinel pile at the distal end [3] .

Fissures in the posterior or anterior midline are common and are not linked to other disorders. Atypical fissures can appear anywhere throughout the length of the anal canal. Malignancy, Crohn's disease, human immunodeficiency virus (HIV) infection, syphilis, and tuberculosis are some of the disorders they're linked to [4].

The specific cause of the disease is unknown. Anal fissures are most commonly caused by the passage of a large, hard stool or anal trauma. Fissures can form even if there is no trauma or constipation. Mechanical hypothesis, in which the anorectal angle causes the most stress posteriorly, Sphincter hypertonicity, and Ischemia, in which both arteriographic examinations and laser Doppler show that the posterior midline is relatively ischemic [5].

There are various treatment options for chronic anal fissure (CAF), but no consensus has so far reached regarding the best modality of treatment. Conservative treatment may heal the ulcers without risking incontinence. However, recurrence is common in these groups of patients [6] 
So most surgeons prefer surgical treatment in $\mathrm{CAF}$ as it expedites ulcer healing with less recurrence. However, incontinence is an important concern. Various surgical approaches for the treatment of CAF anal dilatation (AD) and lateral internal sphincterotomy (LIS) [7].

Many surgeons advocate superiority of LIS over $\mathrm{AD}$. AD has been criticized for recurrence varying from $2 \%$ to $80 \%$, and incontinence up to $51 \%$. But proponents of $\mathrm{AD}$ advocate that when performed in properly controlled manner, it results in significant success rates safely [8].

Lateral internal anal sphincterotomy in the management of chronic anal fissure are safer and more effective than manual dilatation of anus under general or spinal anaesthesia in terms of early symptomatic relief, shorter hospital stay, and less complication rate [9].

\section{Patients and Methods}

This randomized controlled prospective Cohort study.

Each participant who agreed to take part in this study gave written informed consent.

Our study population included 100 patients of chronic anal fissure with pain and bleeding divided into two groups: Group A, 50 patients underwent lateral internal sphincterotomy and Group B 50 underwent manual dilatation of anus.

Inclusion criteria: Patients presenting with chronic typical anal fissure. All patients had symptoms of chronic anal fissure for at least six weeks duration with sentinel pile or skin tag.

Exclusion criteria: Were atypical fissures due to chronic causes like T.B, inflammatory bowel diseases, malignancy etc; patients below the age of 18 years; patients who have undergone previous anal surgeries.

The study was done in the General Surgery Department, The study was conducted for a period of one year from the time of approval.

Pre-operative examination of the participant and adequate operation preparation. The results of the operation are recorded.

\section{Procedures:}

\section{Manual anal dilatation:}

In the lithotomy position, the patient is situated. The index finger of one hand is inserted into the rectum, followed by the index finger of the opposite hand. Gentle lateral retraction with each finger commences for approximately 30 seconds. The long finger is inserted and then the other long finger. With four fingers in place, the anal canal is stretched (massaged) cautiously for 4 minutes. In men, it is easier to stretch the sphincter in the anteroposterior plane because of the narrowness of the pelvic outlet. Sphincter stretch in women, however, should always be performed in the transverse plane (if undertaken at all). Narrowness is not a concern, but disruption of anterior sphincteric support is a real possibility.

\section{Lateral internal anal sphincterotomy:}

The internal anal sphincter was divided up to dentate line and in manual dilatation of anus the sphincter was dilated with gradual four finger technique to relax it. In LIAS technique we made the radial incision in inter-sphincter groove at 3 o'clock position. Gauze lubricated with mycetracin cream was placed and pad was applied which was removed on next morning after surgery.

Most of the patients were discharged within 24 hours after surgery and were advised warm sitz baths, stool softeners agent for two weeks. The post-operative track was assessed, as well as the pain severity recording using the VAS score at 12 hours, 24 hours, and 48 hours.

It is observed that there are problems, Followup is monthly once up to 6 months following surgery.

\section{Results}

A total of 100 patients were included in the study during this period, according to the inclusion criteria. Patient's age in patients with Manual anal dilatation had mean value of $43.74 \pm 12.177 \mathrm{Vs}$ $41.72 \pm 9.331$ years in Lateral internal anal sphincterotomy. Patients sex show that more than half of patients in the MAD groups were female 27(54\%) vs $20(40 \%)$ in LAS group. No significant differences were found according to comorbidity.

The mean \pm SD postoperative pain VAS score of MAD group is higher than LAS group after 12 hours $(6.72 \pm 0.757$ vs $5.46 \pm 0.579)$, 24 hours ( $3.42 \pm$ 0.642 vs $2.86 \pm 0.452)$ and 48 hours $(0.50 \pm 0.544$ vs $0.46 \pm 0.542$ ). There is a significant difference between the MAD and LAS group for postoperative pain VAS score at 12 and 24 hours $(p<0.0001)$. However, there is no significant difference between the MAD and LAS group for postoperative pain VAS score at 48 hours $(p=0.698)$.

The mean \pm SD postoperative hospital stays of MAD group is higher than LAS group $(2.36 \pm 1.064$ vs $1.16 \pm 0.370)$. There is a significant difference 
between the MAD and LAS group for postoperative hospital stays $(p<0.0001)$.

In MAD group, 9 (18.0\%) patients are having hematoma whereas in LAS group, only $2(4.0 \%)$ patient has hematoma. However, there is no statistically significant association between hematoma and type of surgery $(p=0.051)$ (Table 3$)$.

In MAD group, $4(8.0 \%)$ patients are having Nocturnal soiling whereas in LAS group, only 1 $(2.0 \%)$ patient has Nocturnal soiling. However, there is no statistically significant association between Nocturnal soiling and type of surgery $(p=0.362)$.

In MAD group, only $5(10.0 \%)$ patients are having recurrence. Whereas in LAS group, no patient has recurrence. There is no statistically significant association between recurrence and type of surgery $(p=0.056)$.

Table (1): Comparison between the two groups as regard to demographic data.

\begin{tabular}{lccc}
\hline & $\begin{array}{c}\text { MAD Group } \\
(\mathrm{n}=50)\end{array}$ & $\begin{array}{c}\text { LAS Group } \\
(\mathrm{n}=50)\end{array}$ & $\begin{array}{c}p \text { - } \\
\text { value }\end{array}$ \\
\hline Age & $43.74 \pm 12.177$ & $41.72 \pm 9.331$ & 0.651 \\
Sex $n(\%):$ & & & \\
$\quad$ Male & $23(46.0 \%)$ & $30(60.0 \%)$ & 0.229 \\
$\quad$ Female & $27(54.0 \%)$ & $20(40.0 \%)$ & \\
Comorbidity: & & & \\
HTN & $29(58.0 \%)$ & $24(48.0 \%)$ & 0.423 \\
DM & $15(30.0 \%)$ & $22(44.0 \%)$ & 0.214 \\
Dyslipidemia & $10(20.0 \%)$ & $12(24.0 \%)$ & 0.810 \\
\hline
\end{tabular}

MAD: Manual anal dilatation.

LAS : Lateral internal anal sphincterotomy.

Table (2): Mean differences among MAD and LAS group for post-operative pain VAS score.

\begin{tabular}{lccc}
$\begin{array}{l}\text { Postoperative } \\
\text { pain VAS score }\end{array}$ & $\begin{array}{c}\text { MAD Group } \\
(\mathrm{n}=50)\end{array}$ & $\begin{array}{c}\text { LAS Group } \\
(\mathrm{n}=50)\end{array}$ & $\begin{array}{c}p- \\
\text { value }\end{array}$ \\
\hline 12 hours & $6.72 \pm 0.757$ & $5.46 \pm 0.579$ & $<0.001^{*}$ \\
24 hours & $3.42 \pm 0.642$ & $2.86 \pm 0.452$ & $<0.001^{*}$ \\
48 hours & $0.50 \pm 0.544$ & $0.46 \pm 0.542$ & 0.698 \\
\hline
\end{tabular}

MAD: Manual anal dilatation.

LAS : Lateral internal anal sphincterotomy.

Table (3): Association between type of surgery and each of hospital stay and complications.

\begin{tabular}{|c|c|c|c|}
\hline & $\begin{array}{l}\text { MAD Group } \\
\quad(n=50)\end{array}$ & $\begin{array}{l}\text { LAS Group } \\
\qquad(\mathrm{n}=50)\end{array}$ & $\begin{array}{c}p- \\
\text { value }\end{array}$ \\
\hline Hospital stays (days) & $2.36 \pm 1.064$ & $1.16 \pm 0.370$ & $<0.001 *$ \\
\hline \multicolumn{4}{|l|}{ Complications: } \\
\hline Hematoma & $9(18.0 \%)$ & $2(4.0 \%)$ & 0.051 \\
\hline Nocturnal soiling & $4(8.0 \%)$ & $1(2.0 \%)$ & 0.362 \\
\hline Recurrence & $5(10.0 \%)$ & $0(0.0 \%)$ & 0.056 \\
\hline
\end{tabular}

\section{Discussion}

Anal fissure is a stressful disorder. That leads to significant morbidity in young adults. It is a split in the mucosal layer of the distal anal canal that forms a chronic linear ulcer. The common symptoms are severe pain on or after defecation and bleeding per Anus [10]

In the pathogenesis of anal fissures, which is a painful ulceration of the anal canal mucosa, internal sphincter spasm is an accepted cause as a result of the traumatizing effect of hard and large stools which develops secondary to constipation. It is well-accepted that ischemic events are effective in poor healing and recurrence of anal fissures [11]

The exact aetiology remains uncertain. Anal fissures are most common after passing a large, firm stool or an anal trauma. Fissures can form even if there is no trauma or constipation. Mechanical theory, in which the anorectal angle causes the most stress posteriorly, Sphincter hypertonicity, and Ischemia, in which the posterior midline is relatively ischemic by both arteriographic studies and laser Doppler are among the ideas that have been offered [12].

Historically, under regional or general anesthesia, manual anal sphincter dilatation is done to reduce sphincter tone and is a popular procedure in the cure of chronic anal fissure [8]. As a definitive surgical treatment, lateral anal sphincterotomy, in which the internal anal sphincter is separated away from the fissure, commonly in the right or left lateral positions, is currently the current standard of treatment [13].

Our study's goal was to see if the outcomes of total lateral internal anal sphincterotomy and manual dilatation of anus in terms of symptoms and postoperative complications.

This was a randomized controlled study, was conducted on 100 patients of chronic anal fissure with pain and bleeding divided into two groups: Group A, 50 patients underwent lateral internal sphincterotomy and Group B 50 underwent manual dilatation of anus.

In the present study; Patient's age in patients with Manual anal dilatation had mean value of $43.74 \pm 12.177$ Vs $41.72 \pm 9.331$ years in Lateral internal anal sphincterotomy,this correlates with other studies, suggestive of prevalence of the disease in young adults. Patients sex showed that more than half of patients in the MAD groups were female 27 (54\%) vs 20 (40\%) in LAS group. No 
significant differences were found according to comorbidity.

In agreement with our findings, the study of Yucela et al., [14] reported that Patient's age in patients with controlled-intermittent anal dilatation had mean value of $28.7 \pm 7.5$ (19-43) Vs $32.3 \pm 7.9$ (18-49) years in Lateral internal anal sphincterotomy, 10 female, 10 male in controlled-intermittent anal dilatation group, and 13 female, 7 male in Lateral internal anal sphincterotomy, and there were non-statistical significant differences between groups as regard age, sex and comorbidities.

Another study of Razzaq et al., [15] aimed to compare the outcome of anal dilatation and lateral internal sphincterotomy in the care of chronic anal fissure and describe demographic features of all cases, and reported that the age range of the participants was (20-65) years, with mean age of $41.87 \pm 10.31$ years in group A while in group B was $42.52 \pm 10.42$. In group A, 14 patients (35\%) were males and 26 patients $(65 \%)$ were females, while in group B $16(40 \%)$ male and $24(60 \%)$ female patients. Female to male ratio was $1.85: 1$ in group A and 1.5:1 in group B.

In a study reported by Kumar et al., [16] mean age of presentation of anal fissure was 49.5 years which is comparable with our study. In another study done by Hyman [17] mean age was 41.2 (range 21-67) years. Syed et al., [18] described mean age of 39 (12-95 years) in his study. In Garcea et al., [19] study mean age of 40.3 years which is comparable with our study.

Furthe rmore, in the current study, the mean \pm SD postoperative pain VAS score of MAD group is higher than LAS group after 12 hours (6.72 \pm 0.757 vs $5.46 \pm 0.579), 24$ hours $(3.42 \pm 0.642$ vs $2.86 \pm 0.452)$ and 48 hours $(0.50 \pm 0.544$ vs $0.46 \pm$ $0.542)$. There is a significant difference between the MAD and LAS group for postoperative pain VAS score at 12 and 24 hours $(p<0.0001)$. However, there is no significant difference between the MAD and LAS group for postoperative pain VAS score at 48 hours $(p=0.698)$.

In agreement with our findings, the study of Hareesh et al., [1] used a visual analogue scale to evaluate post-operative pain after surgery after 12 hours, 24 hours, and 48 hours (VAS). The MAD group $(6.30 \pm 0.75)$ has a higher mean SD postoperative pain vas score at 12 hours than the LAS group (5.23 \pm 0.57$)$. At 12 hours, the VAS score for postoperative pain differs significantly in between MAD and LAS groups, the mean \pm SD postoperative pain vas score at 24 hours of MAD group
(3.03 \pm 0.81$)$ is higher than LAS group $(2.73 \pm 0.58)$. Furthermore, there is no substantial difference in postoperative pain vas score among MAD and LAS groups at 24 hours $(p=0.131)$. The mean SD postoperative pain vas score for the MAD and LAS groups at 48 hours is $0.43 \pm 0.50$ and $0.47 \pm 0.51$, respectively. However, there is no notable change in postoperative pain vas score among the MAD and LAS groups at 48 hours $(p=0.131)$.

Therapy focuses on breaking the cycle of pain, spasm, and ischemia thought to be responsible for the development of fissure in ano. Operative management includes anal dilatation and lateral internal sphincterotomy. Lateral sphincterotomy is perhaps the operation of choice to perform in patients with chronic anal fissure needing surgical treatment. Postoperative management is simple and rate of healing is faster. However complication such as permanent anal incontinence is associated with the surgery [20]

On the other hand, in the present study, we found that the mean \pm SD postoperative hospital stays of MAD group is higher than LAS group $(2.36 \pm 1.064$ vs $1.16 \pm 0.370)$. There is a significant difference between the MAD and LAS group for postoperative hospital stays $(p<0.0001)$.

In a harmony with our findings, the study of Hareesh et al., [1] reported that the duration of hospital stay after the procedure was also analyzed by grouping them in to two, those who stayed longer than four days and those who stayed for less than four days. In a sample of 30 patients who undergone MAD, the maximum [28 (93.3\%)] patients were stayed less than four days in hospital and $2(6.7 \%)$ patients were stayed more than four days. Whereas all $(100.0 \%)$ patients stayed less than four days in LAS group.

Moreover, Razzaq et al., [15] reported that mean duration of hospital stay was $2.53 \pm 1.11$ days in group A, whereas in group B it was $1.45 \pm 0.58$ days, so again mean duration of hospital stay was statistically significant as $p<0.05$.

As with any surgical procedure, certain complications are associated with MAD group, where $9(18.0 \%)$ patients are having hematoma whereas in LAS group, only 2 (4.0\%) patient has hematoma. However, there is no statistically significant association between hematoma and type of surgery $(p=0.051)$ (Table 3). In MAD group, 4 (8.0\%) patients are having Nocturnal soiling whereas in LAS group, only $1(2.0 \%)$ patient has Nocturnal soiling. However, there is no statistically significant 
association between Nocturnal soiling and type of surgery $(p=0.362)$.

Hashmat and Ishfaq, [21] did a study that showed the incontinence of flatus/faces was present in 18 $(64.3 \%)$ patients at first week which resolved by eight weeks and wound related complications were noted in $4(14.2 \%)$ cases.

In other study done by Zahra et al., [22] that analincontinence occurred in $59.6 \%$ of patients after anal dilatation and in $6.6 \%$ of patients after lateral sphincterotomy which is comparable with our study.

In Razzaq et al., [15] study after anal dilatation significant number of patients developed complications. Eleven (22\%) patients developed flatus incontinence, two (4\%) patients developed fecal incontinence and twenty (40\%) patients complained of haematoma and edema of anal region immediately after dilatation. But there was no case of wound infection after dilatation so complication rate in this study was higher for anal dilatation than after lateral sphincterotomy.

Finally, in our study, we demonstrated that in MAD group, only $5(10.0 \%)$ patients were having recurrence, whereas in LAS group, no patient has recurrence. There is no statistically significant association between recurrence and type of surgery $(p=0.056)$.

Hareesh et al., [1] a sample of 60 patients, during the follow-up period of 6 months, $2(3.3 \%)$ patients landed in recurrence and 58 (96.7\%) patients did not develop recurrence. Patients who have undergone MAD type of surgery, $2(6.7 \%)$ patients were landed in recurrence whereas in LAS type of surgery, no patient had recurrence. This correlate well with the studies conducted by Corman [23] which also reported that there was no statistically significant association between recurrence and type of surgery.

In conclusion, lateral internal anal sphincterotomy is a safer and more successful procedure for treating chronic anal fissures and more effective than manual dilatation of anus under general or spinal anesthesia in terms of early symptomatic relief, shorter hospital stay, and less complication rate. Lateral internal anal sphincterotomy is better procedure than anal dilatation for the surgical treatment of chronic anal fissure.

A further study should be planned with a larger series of patients, including the comparison with continuous pressures and ultrasonographic control.

\section{References}

1- HAREESH G.S. and SOMANGURTHY P.: Comparative study of manual anal dilatation and lateral internal anal sphincterotomy in the treatment of acute anal fissure. International Surgery Journal, 6 (6): 2022-2027, 2019.

2- PANDIT R.K. and JHA V.K.: Lateral Internal Sphincterotomy versus Anal Dilatation in Chronic Anal FissureAn Observational Study. Int. J. Health Sci. Res., 9 (10): 105-110, 2019.

3- NELSON R.L., MANUEL D., GUMIENNY C., SPENCER B., PATEL K., et al.: A systematic review and metaanalysis of the treatment of anal fissure. Techniques in Coloproctology, 21 (8): 605-625, 2017.

4- STEWART Sr D.B., GAERTNER W., GLASGOW S., MIGALY J., FEINGOLD D., et al.: Clinical practice guideline for the management of anal fissures. Diseases of the Colon \& Rectum., 60 (1): 7-14, 2017.

5- PINSK I., CZEIGER D., LICHTMAN D. and RESHEF A.: The long-term effect of standardized anal dilatation for chronic anal fissure on anal continence. Journal of the Korean Society of Coloproctology, Mar. 16, 2020.

6- SRITHARAN H., KUMAR N.K. and IBRAHIM M.I. Management of chronic anal fissures: A narrative review. International Surgery Journal, 7 (4): 1327-1331, 2020.

7- SARKAR S. and KAPUR N.: Lateral internal sphincterotomy under local and spinal anaesthesia for chronic anal fissure: A randomised control trial. Hellenic Journal of Surgery, 88 (6): 398-401, 2016.

8- POPAT A., PANDEY C.P., AGARWAL K., SRIVASTAVA V.P., SHARMA S.M. and DIXIT A.: A comparative study of role of topical diltiazem $2 \%$ organo gel and lateral internal sphincterotomy for the management of chronic fissure in ano. Int. J. Contemp Med. Res., 3 (5): 1363-1365, 2016.

9- EBINGER S.M., HARDT J., WARSCHKOW R., SCHMIED B.M., HEROLD A., POST S. and MARTI L. Operative and medical treatment of chronic anal fissuresa review and network meta-analysis of randomized controlled trials. Journal of Gastroenterology, 52 (6): 663 676, 2017.

10- STEWART D.B., GAERTNER W., GLASGOW S., MIGALY J., FEINGOLD D. and STEELE S.R.: Clinical practice guideline for the management of anal fissures. Diseases of the Colon \& Rectum., 60 (1): 7-14, 2017.

11- GUPTA P.G.: Internal anal sphincterolysis for chronic anal fissure: A prospective, clinical, and manometric study, Am. J. Surg., 194 (1): pp. 13-16, 2007.

12- HARDY J.D. and KUKORA J.S.: Anal fissure. In Hardy's Textbook of surgery, 2 nd Edition, Philadelphia, 626-8, 1998.

13- MORRIS P.J. and MALT R.A.: Fissure in Ano. Oxford textbook of surgery, New York, 1139-40, 1994.

14-YUCELA T., DOGAN GONULLUB, MAHMUT ONCUC, FERDA NIHAT, KOKSOYB SIBEL GURDAL and OZKAND OMER AYCAN: Comparison of controlledintermittent anal dilatation and lateral internal sphincterotomy in the treatment of chronic anal fissures: A prospective, randomized study, International Journal of Surgery, Volume 7, Issue 3, Pages 228-231, 2009. 
15- RAZZAQ M.A., GHULAM YASIN, AMNA SHAHAB and GHULAM YASIN: Compare the outcome of anal dilatation and lateral internal anal sphincterotomy in the treatment of chronic anal fissure, P J M H S Vol. 13, No. 3, Jul-Sep, 2019.

16- KUMAR D., ANIL N., NEERAJ K. and AVINASH P. A prospective, randomize study of comparison of lateral internal sphincterotomy versus Lord's anal dilatation in chronic anal fissure. Int. Surg. J., 5 (3): 1026-30, 2018.

17- HYMAN N.: Incontinence after lateral internal sphincterotomy: A prospective study and quality of life assessment. Dis. Colon Rectum., 47: 35-8, 2004.

18- SYED S.A., WARIS S., AHMAD E., SAEED N. and ALI B.: Lateral internal anal sphincterotomy for anal fissure: With or without associated anorectal procedures. J. Coll. Phy. Sur. Pak., 13: 436-9, 2003.
19- GARCEA G., SUTTON C. and MANSOORI S.: Lateral sphincterotomy for the treatment of chronic anal fissure. Colorectal Dis., 5: 311-4, 2004.

20- BABU P. and RAO K.S.: A Comparative Study of Lateral Sphincterotomy and 2\% Diltiazem Gel Local Application in the Treatment of Chronic Fissure in ANO. Journal of clinical and diagnostic research: JCDR, 8 (10), NC01NC2. https://doi.org/10.7860/JCDR/2014/10480.4925, 2014.

21- HASHMAT A. and ISHFAQ T.: Chemical versus surgical sphincterotomy for chronic fissure in ano. J. Coll. Physicians Surg. Pak., 17: 44-7, 2007.

22- ZAHRA F., MAJID A., WAHEED M. and CHOHAN S.: Lateral internal sphincterotomy versus anal dilatation. Ann. King Edward Med. Coll., 10: 43-4, 2004.

23- CORMAN M.L.: Anal fissure in Colon and Rectal Surgery. Philadelphia, 116-131, 1999.

\section{مقارنة نتائج ما بعد الجراحة بين التوسيع اليدوى اليدا

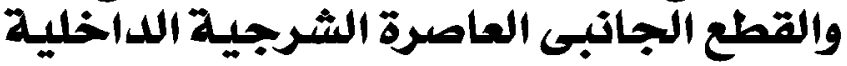

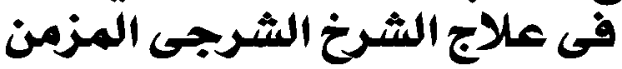

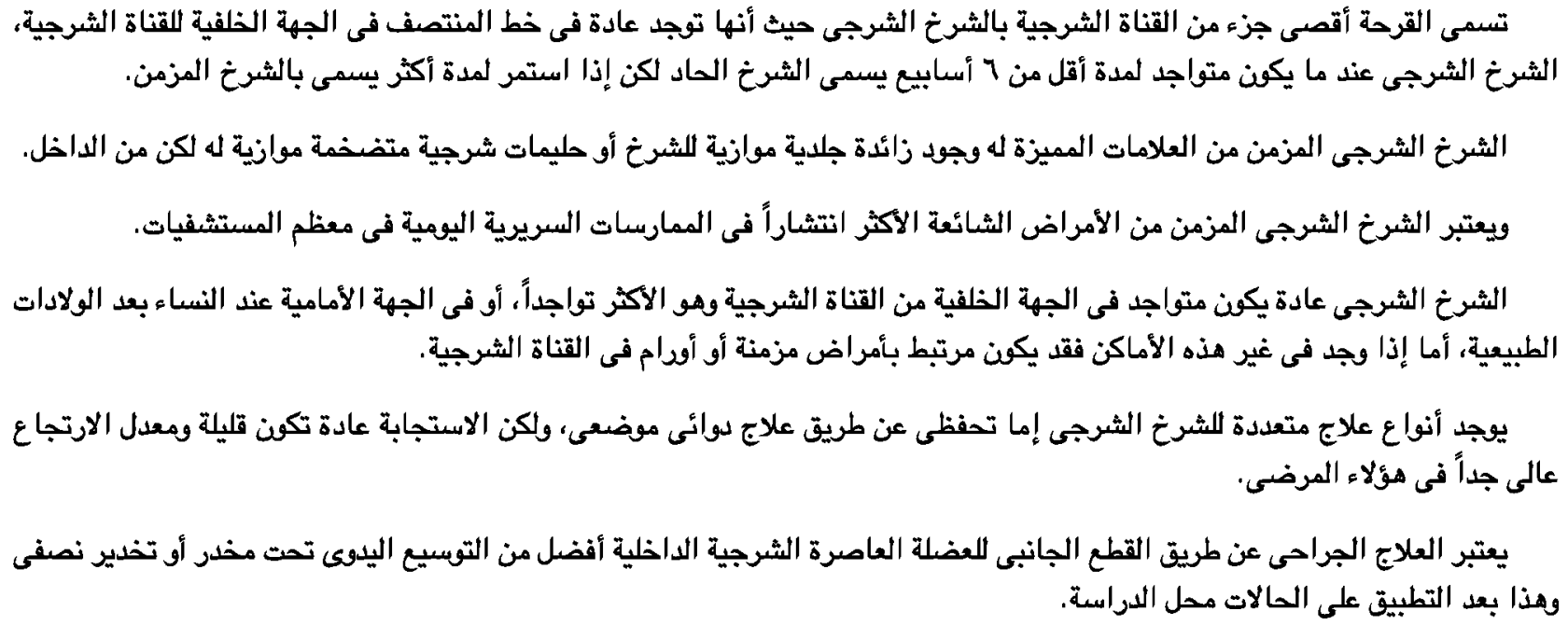

